\title{
Investigations of the Mechanical Properties of DLP 3D Printed Graphene/Resin Composites
}

\author{
Muammel M. Hanon ${ }^{1,2 *}$, Arsany Ghaly ${ }^{3}$, László Zsidai ${ }^{3}$, \\ Zoltán Szakál $^{3}$, István Szabó ${ }^{3}$, László Kátai ${ }^{3}$ \\ ${ }^{1}$ Mechanical Engineering Doctoral School, Szent István Campus, \\ MATE University, Páter Károly u. 1, 2100 Gödöllö, Hungary; \\ sharba.muammel.m.hanon@phd.uni-szie.hu \\ ${ }^{2}$ Baquba Technical Institute, Middle Technical University (MTU), \\ Muasker Al-Rashid Street, 10074 Baghdad, Iraq \\ ${ }^{3}$ Institute of Technology, Szent István Campus, MATE University, \\ Páter Károly u. 1, 2100 Gödöllö, Hungary; \\ Ghaly.Arsany@stud.uni-mate.hu, zsidai.laszlo@uni-mate.hu, \\ Szakal.Zoltan@uni-mate.hu, Szabo.Istvan@uni-mate.hu, \\ katai.laszlo@uni-mate.hu
}

\begin{abstract}
Three-dimensional (3D) printing is an astonishing technology that has enabled the manufacturing of complex structures, with comparatively shorter times and the least material consumption. Currently, Graphene is gaining remarkable attention, as a filler material, used for the reinforcement of metal and polymer composites. In this paper, the $3 D$ printing system, based on the digital light processing (DLP) method, is employed for the fabrication of bio-based resin specimens, to estimate their dynamic mechanical properties. For this purpose, two graphene concentrations $(0.5$ and 1 wt\%) were mixed in resin (matrix) by a vortex mixer/shaker. The resultant mixture, in addition to the neat resin, was utilized for producing the test pieces, at three different layer thicknesses $(35,50,100 \mu \mathrm{m})$. A comparison of the mechanical properties, between the DLP-printed neat resin and graphene/resin composite materials, was accomplished, to illustrate the impact of filler (graphene nanoplatelets) and the printing process settings (layer thickness). These determinants were assessed according to the microstructure and tensile characteristics of the examined materials. The results of scanning electron microscopy (SEM) showed a fairly even dispersion of graphene in the resin matrix. Moreover, it was found that smaller layer thicknesses provide a higher tensile strength. Further, a decrease in Young's modulus, tensile strength and elongation can be observed, with higher graphene concentrations.
\end{abstract}

Keywords: Photopolymerization; $3 D$ Printing settings; Graphene platelets; Polymer composites; Tensile strength; Young's Modulus 


\section{Introduction}

A universal method for enhancing the mechanical properties of machined items has not yet been suggested, despite the reports of numerous attempts. Thus, the investigation and development of new materials that demonstrate high potential outcomes are still being pursued. Graphene is one of the new materials exhibiting an extraordinary prospect for mechanical property enhancement. It has attracted considerable attention in the materials field over the last decade [1].

Due to the multi-functionality of this $2 \mathrm{D}$-atomic crystal which combines unique properties, such as, high electron mobility $\left(250,000 \mathrm{~cm}^{2} / \mathrm{Vs}\right)$ at room temperature, elevated thermal conductivity $(5000 \mathrm{~W} / \mathrm{mK})$, large surface area in the order of $2630 \mathrm{~m}^{2} / \mathrm{g}$, good electrical conductivity and a high modulus of elasticity, roughly $1 \mathrm{TPa}$, making it attractive for use in a broad range of applications [2]. The list of potential applications includes electromechanical systems, high-end composite materials, solar cells and supercapacitors [3].

Simultaneously additive manufacture (3D printing) is gaining more and more momentum owing to its versatility [4]. The ability of 3D Printing to create solid bodies layer by layer is magnificent [5] [6]. In mechanical engineering today's world, the applications of additive manufacture are very useful for the development and research of various components, covering from simple structures utilized in everyday life, up to complicated elements, in aerospace applications [7]. 3D printing supplies many advantages, such as, precision, simplicity, reliability, etc. [8].

One of the earliest additive manufacturing techniques was Stereolithography (SLA or SL) also known as optical fabrication, stereolithography apparatus, resin printing, or photo-solidification, which was invented by Chuck Hull in 1984 [9]. It harnesses the power of light, especially the ultraviolet light (UV), to cause chemical monomers and oligomers, to cross-link together, to create polymers, this process is called polymerization [10]. Digital light processing (DLP) is an additive manufacturing technology, also based on the photopolymerization principle, as SLA [11]. This method uses photocurable resins (polymer) to rapidly build an individual layer, of the desired 3D object, through spatially controlled solidification, using ultraviolet projected light [12]. It is characterized with less shrinkage, high resolution, produces smooth surface elements and fast performance [13] [14].

The study of graphene-based composites' mechanical properties is becoming increasingly common in academia and industry. Three techniques are being used to prepare graphene-composite or graphene oxide-composite:

In situ intercalative polymerization, where graphene or graphene oxide is first swollen (in the liquid monomer), then a suitable initiator is dispersed and polymerization reaction progresses by heat or radiation [15]. 
Melt intercalation, graphene or graphene oxide is mechanically mixed with polymer (thermoplastic) at raised temperatures [16]

Solution intercalation, which involves three steps: dispersion of graphene or graphene oxide in a suitable solvent, polymer addition, and removal of solvent [17].

The previous studies have reviewed the mechanical properties of graphene/polymer composites. The melt intercalation technique is usually used because controlling mixing and printing parameters are simple. The graphene has done a tremendous job in enhancing the mechanical properties of the polymers using the fused deposition modeling (FDM) technique [18-21]. Showing an increase in Young's modulus, stiffness, thermal and electrical conductivity. Some other researchers used powder bed fusion technology and added graphene to a metallic matrix [22].

Implementing graphene into photopolymerization technology (such as SLA/DLP) is very complex to control the homogeneity of the graphene within the polymer matrix (solution intercalation). This resulting in a nanocomposite material which is a perfect condition where layers of graphene are completely dispersed into the polymer matrix. The main challenge is how to diffuse graphene or graphene oxide equitably within the bulk. As a result, the number of published articles, is not sufficient to make a concrete conclusion concerning the effect of graphene on mechanical properties.

In all the previous work, especially using the photopolymerization method, the researchers were using sophisticated techniques to mix the graphene or the graphene oxide into the polymer matrix. The proportions that were used were under $1 \mathrm{wt} \%$, in a controlled temperature. In this work, the effect of graphene on the mechanical (tensile) characteristics of graphene/resin composite 3D printed specimens, by the DLP technique, was studied. Meanwhile, robust industrial measures were carried out to mix the graphene within the resin using a relatively higher graphene percentage compared to the previous work. The composite mixture was with two graphene concentrations $(0.5$ and $1 \mathrm{wt} \%)$. The $3 \mathrm{D}$ printing was performed employing three printing layer thicknesses $(35,50,100 \mu \mathrm{m})$. In addition, the microstructural features of graphene/resin composite were examined. Based on the obtained results, the influences of graphene existence and varying process parameters (layer height) on the mechanical properties of the composite were investigated. 


\section{Materials and Methods}

\subsection{Materials and Preparation of Composite}

The Bio-based Photopolymer resin (eResin PLA) supplied by Shenzhen Esun Industrial Co., Ltd (China) was used as a matrix for the composite filler. This resin is a light-curable chemical liquid, with a white color. It could be cured at a wavelength range from 395 to $405 \mathrm{~nm}$, to convert to a solid state. At $25^{\circ} \mathrm{C}$, it has a viscosity of 200-300 MPa.s, meanwhile, its density is $1.07-1.13 \mathrm{~g} / \mathrm{m}^{3}$. The chemical composition of the utilized photopolymer resin material as specified in the datasheet of the product is presented in Table 1 [23].

Table 1

Chemical ingredients of the employed photopolymer resin material [23]

\begin{tabular}{|l|l|}
\hline Chemical name & Percentage by weight $(w \mathbf{\%})$ \\
\hline Polyurethane acrylate & $30 \% \mathrm{~min}$ \\
\hline Monomer & $30 \% \mathrm{~min}$ \\
\hline Photo initiators & $5 \% \max$ \\
\hline Color pigment & $5 \% \max$ \\
\hline
\end{tabular}

Graphene nanoplatelets purchased from Nanografi Nano Technology Co. (Ankara, Turkey) [24] consisting of platelet-shaped graphene sheets (short stacks) in a planar form. This nanomaterial is colored black and with a purity of $99.90 \%$. Its particles having a diameter of $1.5 \mu \mathrm{m}$ and an average thickness of $3 \mathrm{~nm}$ besides a surface area of $800 \mathrm{~m}^{2} / \mathrm{g}$. Due to their pure graphitic composition, the graphene nanoplatelets are characterized by excellent thermal and electrical conductivity (1500-1980 s/m) [24].

The flowchart displayed in Figure 1 represents the sequence and steps of the experimental work that was accomplished in the present study. The experiments were conducted at Szent István Campus, MATE University, Gödöllő, Hungary, specifically in 3D printing and mechanical testing laboratories. Both 3D printing resin material (matrix) and graphene (filler) were used to prepare the composite and then fabricating the specimens. These materials concentration was weighed by means of a Sartorius brand laboratory scale (Sartorius AG Co., Gottingen, Germany) which has an accuracy of $0.001 \mathrm{~g}$. Thereafter, the materials were put into a container to prepare the mixture. This container is a centrifuge tube $(50 \mathrm{ml}$ in volume) made of polypropylene plastic with a conical bottom shape. Further, aluminum foil was used to fully cover the tube and make it opaque to avoid any light transmission from the lab room into the resin which may cure it. A vortex mixer shaker (FOUR E's brand, FOUR E's Scientific Company, Guangzhou, China) device has been used to mix the components of the composite material (resin with graphene) put in the centrifuge tube at $3000 \mathrm{rpm}$ shaking speed. 
When the tube's conical bottom press onto the rubber piece of vortex mixer which is in contact with an electric motor, the rubber cap oscillates immediately in a circular motion owing to the motor running (See the vortex mixer/shaker in Figure 1). Thus, a vortex is created inside the tube as a consequence of the motion conveyed to the liquid. The mixture converts to fully black colored in a couple of seconds after starting the mixing process by the vortex mixer, despite the neat resin is white. This intimates the dispersion of graphene nanoplatelets throughout the resin. In order to increase the likelihood of a homogeneous mixture, the mixing process lasted for five minutes. Using this mixture (graphene/resin composite) as well as the neat resin (to determine the effect of graphene), the tensile testing specimens were fabricated with different parameters by $3 \mathrm{D}$ printing.

Moreover, post-processing was performed after the samples were printed to ensure that the resin was entirely cured. The post-printing process included heating the specimens for 30 minutes in the oven up to $60{ }^{\circ} \mathrm{C}$. Then, these objects were exposed for 30 minutes to ultraviolet light (UV) at a wavelength of $405 \mathrm{~nm}$ as per recommended by Formlabs [25]. A schematic diagram of the UV light cure unit used is depicted in Figure 2a. This UV cure chamber was made from scratch where a nail salon UV lamp with 36 watts was modified to fit into a box for holding up the specimens. Aluminum (foil) mirror was employed for lining the box from inside to decrease the light losses by increasing the reflectivity. In addition, a transparent plastic sheet was added, as a shelf inside the box, to ensure UV light exposure, to all sides of specimens, at once.

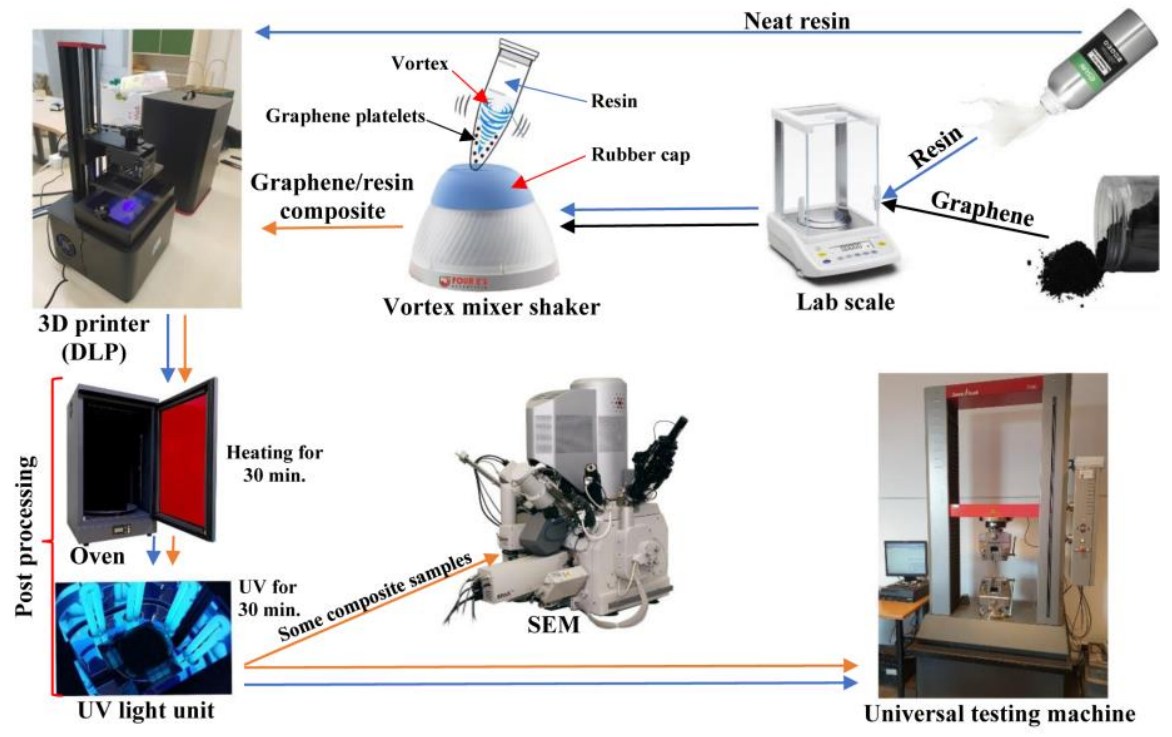

Figure 1

Flowchart for the experimental work sequence 
Some graphene/resin composite samples were examined by scanning electron microscope (SEM) to inspect whether the graphene platelets were successfully incorporated. To this end, an EVO 40 SEM (Carl Zeiss AG Co., Oberkochen, Germany) was used to take many images for the surface morphology of the samples at various magnifications. Finally, the tensile tests were carried out for all manufactured specimens. More details about the 3D printing of specimens and tensile tests are described in the subsequent sections.

\subsection{D Printing of Test Specimens}

Tensile test samples were produced with the WANHAO D7 V1.5 3D printer operating, according to a digital light processing (DLP) 3D printing method, that uses a photo-polymerization mechanism. AutoCAD program was utilized to design the specimens' 3D model. CreationWorkshop software which has as its file extension format, ".cws", was recommended by the manufacturer for the purpose of slicing the model. The course of action (procedure commands) of the sliced 3D model was uploaded into the $3 \mathrm{D}$ printer in accord with the parameters set during the slicing.

The tensile test pieces were the dog-bone shape modeled according to the standard ISO 527-2: 2012 type 1BA [26]. The specimens were built at an On-edge orientation (see Figure 2c) owing to the reliability of this build orientation as confirmed in literature [27-29]. These samples were fabricated at three layer heights $(100,50$, and $35 \mu \mathrm{m})$ to investigate the influence of print layer thickness (see Figure $2 \mathrm{~d}$ ) on the mechanical properties. In terms of the printing materials, neat (pure) resin as well as graphene/resin composite with two different graphene concentrations $(0.5$ and $1 \mathrm{wt} \%)$ were used for the manufacture of specimens. This was done to assess the effect of graphene platelets' existence. At least, four identical specimens were printed for each print condition, i.e., for each individual manufacturing parameter, four similar pieces have been prepared. The actual physical appearance of the printed samples is pictured in Figure $2 \mathrm{~b}$.

Due to the diversity of parameters (different materials and print thicknesses), the specimens were highlighted with a description code for each one using various numbers and colors for easier traceability. The description included the layer height, graphene content, and the order of the sample within the same set. These identifying codes were manifested at the top face of the test pieces as displayed in Figure $2 b$. The tensile test specimens of graphene/resin composite material still fixed on the printing platform (after printing directly and before post-processing) are shown in Figure 2e. 


\subsection{Tensile Tests}

As mentioned in section 2.2, the tensile test pieces were modeled following ISO 527-2, type 1BA, with an overall dimension of $75 \mathrm{~mm} \times 10 \mathrm{~mm} \times 2 \mathrm{~mm}$ (length $\times$ width $\times$ thickness, consecutively) for the measurement of tensile strength/modulus. Prior to measurement, the samples were conditioned for 24 hours in a room with a climatic of $23-25{ }^{\circ} \mathrm{C}$ and $45-50 \%$ as temperature (T) and relative humidity $(\mathrm{RH})$, respectively. The tensile mechanical properties were examined for all printed specimens by a universal testing machine (Zwick / Roell Z100, Germany) with employing the standard for tensile testing of polymers ISO 527 [30]. During the test, both ends of the sample were attached to the grip, and testing was performed at a velocity of $5 \mathrm{~mm} / \mathrm{min}$ until the test piece broke down. In order to yield confident data, four samples were tested for each condition and their average was calculated. The essential mechanical properties including Young's modulus (modulus of elasticity), ultimate tensile strength (UTS), elongation at break, and elongation at UTS were obtained from each specimen's stress-strain curve. The modulus of elasticity (E) was calculated using Hooke's law, in all stress-strain points:

$E=\sigma / \varepsilon$

where $\sigma$ is the tensile stress (applied force/cross-sectional area) and $\varepsilon$ is the tensile strain (change in length/initial length). For reliable results, the Young's modulus was determined by taking the gradient of the line on two points fitted at the $10 \%$ and $60 \%$ in the stress-strain plot. The stress-strain curves gained from specimens were compared to investigate the variance in specimens' mechanical properties fabricated in different conditions (layer height and graphene concentration). Table 2 provides a summary of the tensile specimen dimensions used and parameters performed throughout the tests.

Table 2

The specimen dimensions and the implemented parameters during the tensile tests

\begin{tabular}{|c|c|c|c|}
\hline \multicolumn{3}{|l|}{ Parameter } & Value \\
\hline \multirow{4}{*}{$\begin{array}{l}\text { Specimen } \\
\text { dimensions }\end{array}$} & \multicolumn{2}{|l|}{ Overall length } & $75 \mathrm{~mm}$ \\
\hline & \multicolumn{2}{|l|}{ Gauge length } & $25 \mathrm{~mm}$ \\
\hline & \multirow{2}{*}{ Gauge cross-section } & Width & $5 \mathrm{~mm}$ \\
\hline & & Thickness & $2 \mathrm{~mm}$ \\
\hline \multicolumn{3}{|c|}{ Testing standard } & ISO 527-1:2012 \\
\hline \multicolumn{3}{|c|}{ Tensile velocity, $v$} & $5 \mathrm{~mm} / \mathrm{min}$ \\
\hline \multicolumn{3}{|c|}{ Relative humidity, RH } & $45-50 \%$ \\
\hline \multicolumn{3}{|c|}{ Ambient temperature, $T$} & $23-25^{\circ} \mathrm{C}$ \\
\hline
\end{tabular}


(a)

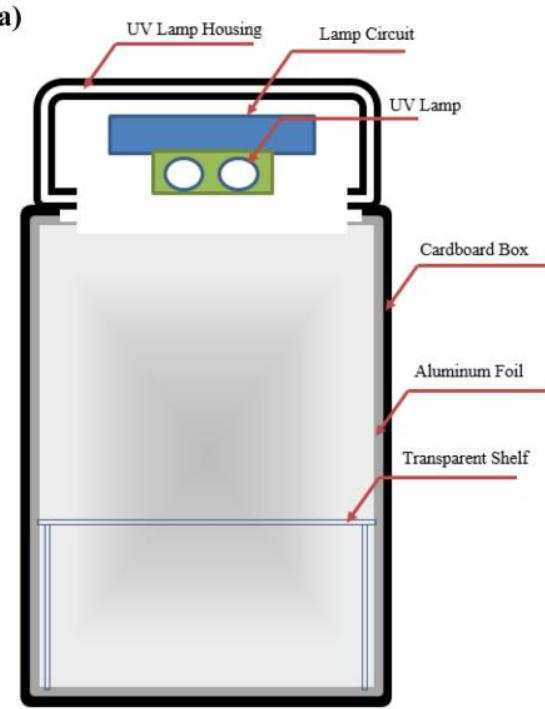

(b)

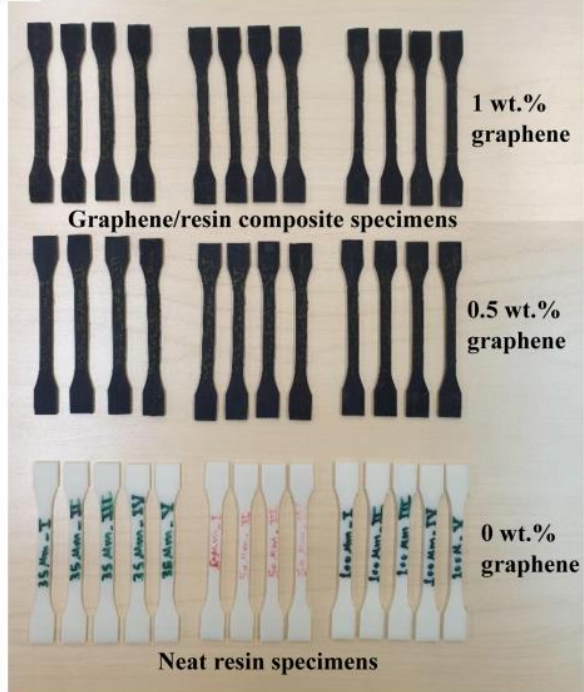

(c)
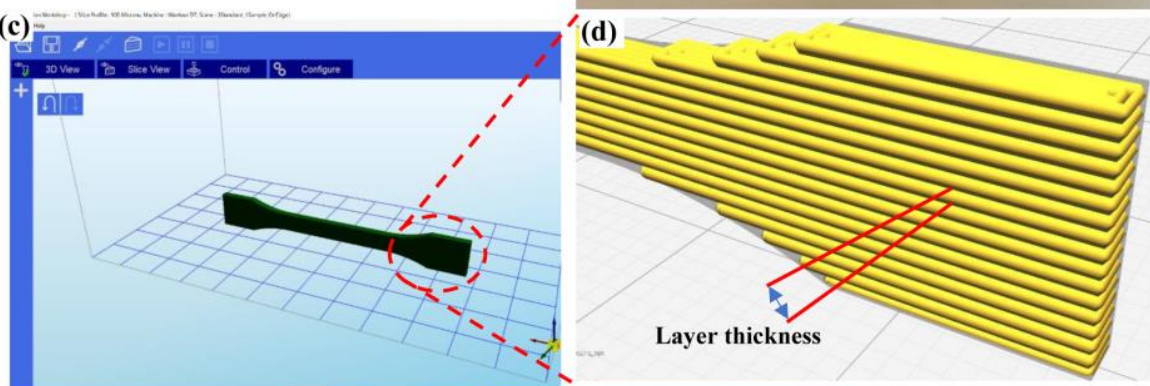

(e)

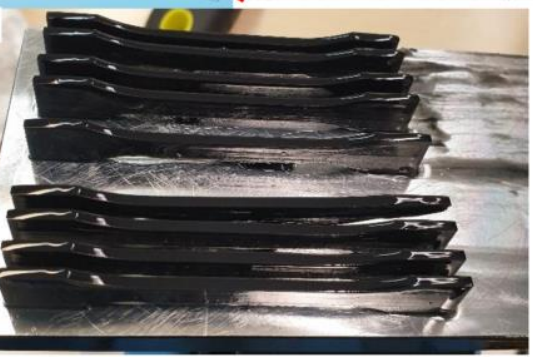

Figure 2

(a) Schematic of the used ultraviolet light unit. (b) The 3D printed tensile test specimens with different graphene content. (c) Screenshot from the slicing software for the tensile sample printed at On-edge build orientation. (d) Illustration for print layer height of test piece during the manufacture. (e) Specimens after printing instantly. 


\section{Results and Discussion}

\subsection{Microstructure Investigation}

After mixing the graphene platelets with resin by the Vortex mixer/shaker, some pretest specimens were printed. The morphology and microstructure of these samples' surfaces were investigated by taking SEM images (Figure 3a-d). It was mentioned in Section 2.1 that the graphene platelets have a diameter of $1.5 \mu \mathrm{m}$ and an average thickness of $3 \mathrm{~nm}$, thus they are quite tiny. Figure $3 \mathrm{a} \& \mathrm{~b}$ displays the surface morphology of the graphene/resin specimen where it can be seen that the graphene nanoparticles were successfully incorporated into the eventually printed structure. The graphene nanoplatelets seem to be spread throughout the matrix fairly. Some pits are also visible at the surface which indicates the existence of porosity that might be more prominent in the internal structure of printed pieces. The interior morphology of a fractured specimen is depicted in Figure $3 c \& d$. The graphene nanoplatelets were also found and have appropriately integrated within the bulk.

In other respect, increasing the graphene addition to the polymer matrix made it somehow arduous to be printed especially beyond $2 \mathrm{wt} \%$. This is due to the graphene nanoparticles give rise to scattering the UV light which causes difficulty to the resin for being fully cured. Numerous research in literature have reported that the photopolymerization 3D printing (light-based systems) of graphene/polymer composite could be only achieved with a low concentration of graphene, reached up to $0.1 \mathrm{wt} \%$ in these works [31] [32] and $0.5 \mathrm{wt} \%$ in others $[16,33]$. However, for this study, the preparation method of the graphene/resin composite (by Vortex mixer/shaker) sounds excellent, as the composite material was efficiently printed with even a graphene concentration of $1 \mathrm{wt} \%$.

\subsection{Mechanical Behavior}

The mechanical behavior of DLP 3D printed components is discussed in this chapter. To investigate the effect of strengthening the polymer composite, using graphene, on the mechanical properties, tensile test samples were $3 \mathrm{D}$ printed under different printing conditions. The variables of the experiment included the print layer thickness (height) and the graphene concentration to resin. Three print layer heights $(35,50$, and $100 \mu \mathrm{m})$ were examined and two graphene ratios $(0.5$, and $1 \mathrm{wt} \%$ ) were assessed. An average of four identical test pieces was taken for each inspected condition. The mechanical properties were reviewed through evaluating the stress-strain curves which implicitly assisted to obtain Young's modulus, ultimate tensile strength (UTS), elongation at break, and elongation at UTS for each specimen's data. The subsequent sections present the influence of layer thickness firstly, and then followed by the impact of graphene attendance. 

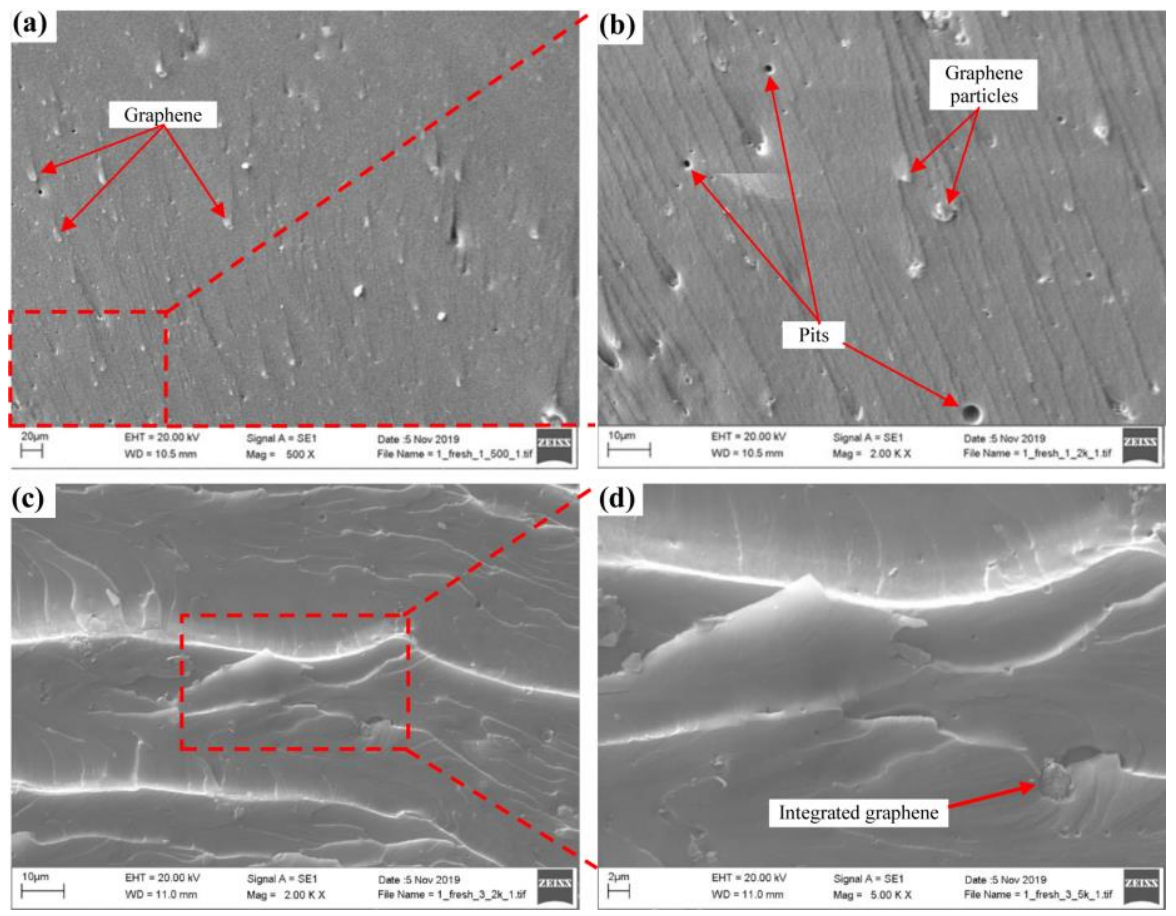

Figure 3

The morphology of graphene/resin specimen (a) \& (b) at the surface; (c) \& (d) in the interior structure after fracture

\subsubsection{Impact of Layer Thickness}

The stress versus strain curves under a load of tensile testing for different layer thickness $(35,50$, and $100 \mu \mathrm{m})$ specimens are demonstrated in Figure 4. These curves for the test piece materials of 0 (neat resin), 0.5 , and $1 \mathrm{wt} \%$ graphene concentration are displayed in Figure $4 \mathrm{a}, \mathrm{b}$, and c, respectively. In general, the highest tensile strength attitude was observed in the layer thickness of $35 \mu \mathrm{m}$ (lowest height). This is because the strength of 3D printed objects enhances with the increase in the number of the layers [34], as the lower the layer height the more the number of layers. Therefore, the neat resin specimens reported a reduction of $11.62 \%$ and $22.1 \%$ in the average values of the tensile stress for 50 and $100 \mu \mathrm{m}$ layer thickness, consecutively, as compared to the $35 \mu \mathrm{m}$. Further, a decrease of " $7.25 \%$ and $25.78 \%$ " for the $50 \mu \mathrm{m}$ layer height and " $23.13 \%$ and $35.52 \%$ " for the $100 \mu \mathrm{m}$ was noticed in the $0.5 \mathrm{wt} \%$ and $1 \mathrm{wt} \%$ graphene content samples, respectively, against the $35 \mu \mathrm{m}$ specimens. This improvement in the $3 \mathrm{D}$ printed parts' tensile properties when the printing layer thickness reduces was also observed in other published research [35] [36]. They attributed the weaker 
mechanical properties of the greater layer thickness to the bigger existed gaps. Which in turn prompts the porosity to develop in the element's cross-section and accelerates the failure.
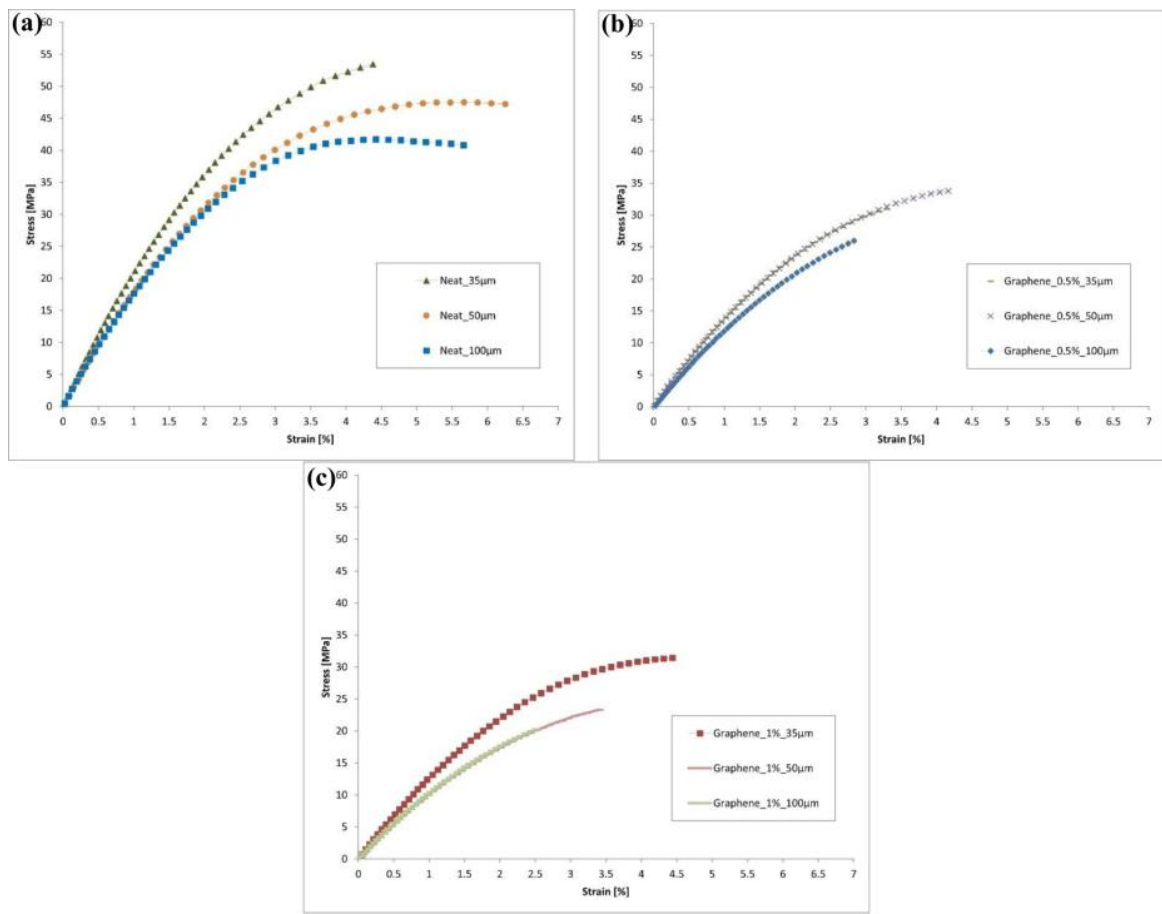

Figure 4

Tensile stress-strain curves of various layer thickness specimens at (a) Neat resin material; Composite with graphene concentration of (b) $0.5 \mathrm{wt} \%$ and (c) $1 \mathrm{wt} \%$

\subsubsection{Influence of Graphene Existence}

Two different graphene concentrations of 0.5 and $1 \mathrm{wt} \%$ were tested. The charts in Figure 5 demonstrate how the addition of graphene, has affected the tensile stress and strain of DLP 3D printed resin, at various layer heights. The layer thickness specimen curves of 35, 50, and $100 \mu \mathrm{m}$ are drawn in Figure 5 (a), (b) and (c), respectively. Moreover, Figure 5 (d) displays a comparison of stress-strain curves among all examined conditions. Based on these results, Young's modulus, UTS, elongation at UTS and elongation at break were calculated and represented in Figure 6 (a), (b), (c), and (d), consecutively. Furthermore, the values of all results with their standard deviation (SD), were summarized and tabulated in Table 3. 

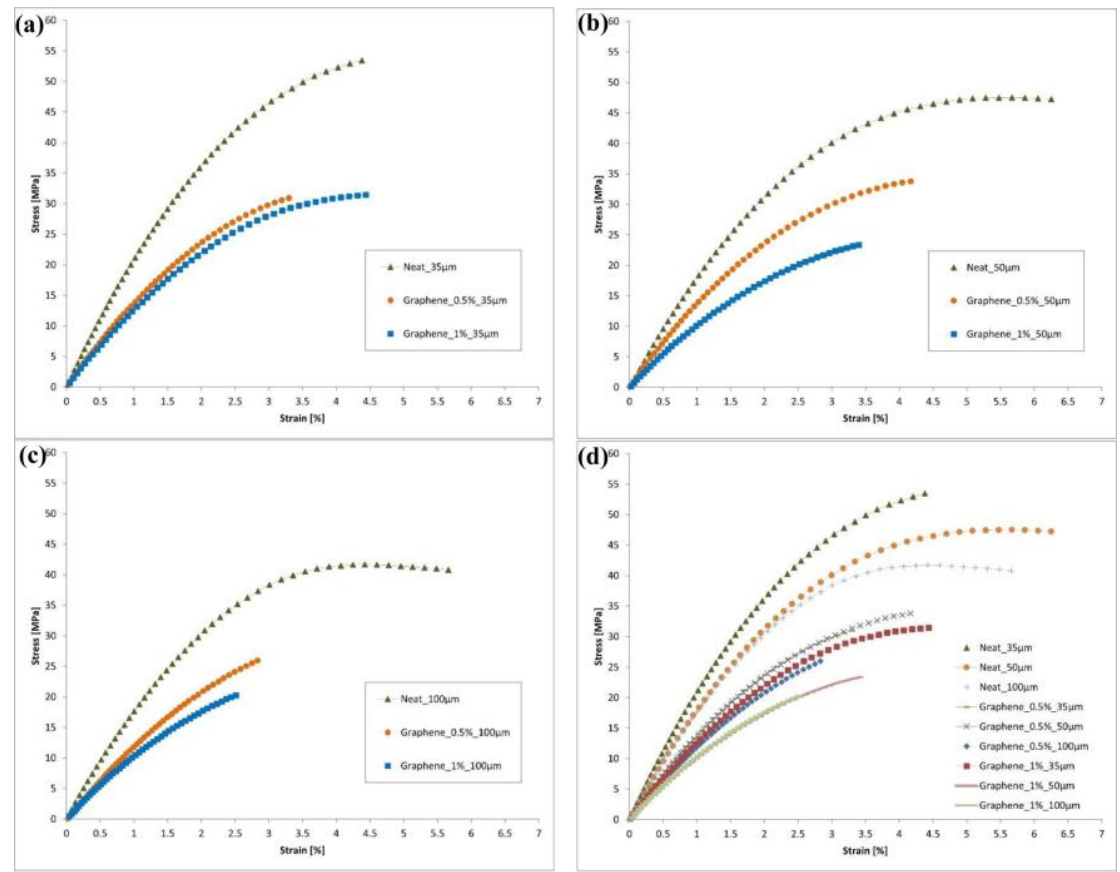

Figure 5

Tensile stress-strain curves of various graphene concentration $(0,0.5,1 \mathrm{wt} \%)$ specimens at layer thickness of (a) 35, (b) 50, and (c) $100 \mu \mathrm{m}$; (d) comparison among all the used conditions

(a)
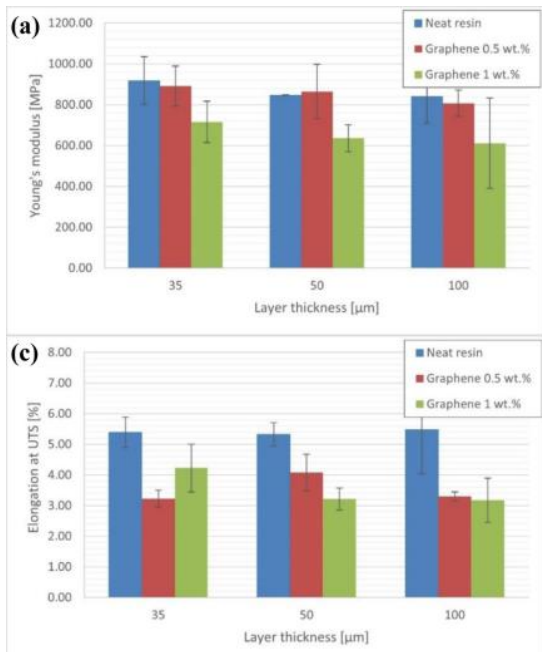
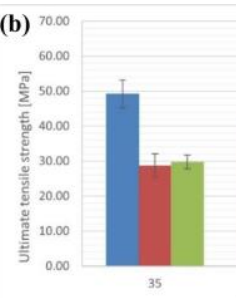

(d)

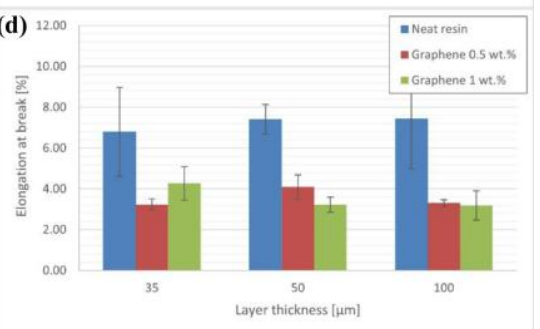

Figure 6

Comparison of mechanical behavior under different graphene concentrations and printing layer thickness in terms of (a) Young's modulus, (b) ultimate tensile strength (UTS), (c) elongation at UTS, and (d) elongation at break 
Table 3

Average values aside with their standard deviation (SD) of Young's modulus, ultimate tensile strength (UTS), elongation at UTS, and elongation at break of samples manufactured in all tested conditions

\begin{tabular}{|c|c|c|c|c|c|c|c|c|c|c|}
\hline \multicolumn{3}{|c|}{ Printing parameter } & \multirow[b]{2}{*}{$\begin{array}{c}\text { Young's } \\
\text { modulus } \\
{[\mathrm{MPa}]}\end{array}$} & \multirow[b]{2}{*}{$\begin{array}{l}\text { SD } \\
( \pm)\end{array}$} & \multirow[b]{2}{*}{$\begin{array}{c}\text { UTS } \\
{[\mathrm{MPa}]}\end{array}$} & \multirow[b]{2}{*}{$\begin{array}{l}\text { SD } \\
( \pm)\end{array}$} & \multirow[b]{2}{*}{$\begin{array}{c}\text { Elong. } \\
\text { at UTS } \\
{[\%]}\end{array}$} & \multirow[b]{2}{*}{$\begin{array}{l}\text { SD } \\
( \pm)\end{array}$} & \multirow{2}{*}{$\begin{array}{c}\text { Elong. } \\
\text { at } \\
\text { break } \\
{[\%]} \\
\end{array}$} & \multirow[b]{2}{*}{$\begin{array}{l}\text { SD } \\
( \pm)\end{array}$} \\
\hline Material & \begin{tabular}{|c|} 
Graphene \\
content \\
$(\mathrm{wt} \%)$
\end{tabular} & $\begin{array}{c}\text { Layer } \\
\text { height } \\
{[\mu \mathrm{m}]}\end{array}$ & & & & & & & & \\
\hline \multirow{3}{*}{ Neat resin } & \multirow{3}{*}{0} & \begin{tabular}{|l|}
35 \\
\end{tabular} & 917.66 & 116.80 & 49.17 & 3.96 & 5.39 & 0.49 & 6.79 & 2.17 \\
\hline & & 50 & 847.46 & 1.81 & 45.17 & 3.31 & 5.33 & 0.38 & 7.40 & 0.73 \\
\hline & & 100 & 841.78 & 132.46 & 45.16 & 4.88 & 5.48 & 1.44 & 7.42 & 2.45 \\
\hline \multirow{6}{*}{$\begin{array}{l}\text { Graphene } \\
\text { composite }\end{array}$} & \multirow{3}{*}{0.5} & 35 & 890.87 & 98.25 & 28.74 & 3.30 & 3.23 & 0.27 & 3.24 & 0.28 \\
\hline & & 50 & 864.79 & 132.81 & 34.82 & 0.79 & 4.09 & 0.59 & 4.09 & 0.59 \\
\hline & & 100 & 807.09 & 63.90 & 26.66 & 2.80 & 3.30 & 0.15 & 3.31 & 0.16 \\
\hline & & 35 & 715.85 & 101.54 & 29.76 & 1.96 & 4.23 & 0.78 & 4.27 & 0.82 \\
\hline & & 50 & 635.78 & 65.69 & 20.53 & 3.82 & 3.22 & 0.36 & 3.22 & 0.37 \\
\hline & & 100 & 611.06 & 221.48 & 18.23 & 4.22 & 3.18 & 0.72 & 3.19 & 0.72 \\
\hline
\end{tabular}

Despite the graphene is characterized with high mechanical qualities, however, it can be seen throughout the whole obtained results that the mechanical behavior was not improved when the graphene nanoplatelets were integrated. Also, it was noticed that with increasing the graphene concentration further, a much worse mechanical attitude was acquired. This might be attributed to the bubbles created within the matrix bulk during the DLP 3D printing due to the addition of graphene. Considering that the graphene contributes to scattering the UV light and decreases the curing which results in the presence of adjacent unpolymerized regions. In turn, played a role to boost the porosity existence, and subsequently, the effects of graphene platelets' stiffening and strengthening were critically hampered [31]. Markandan and Lai have observed large pores at higher graphene content (through microscopy images) of SLA-printed graphene/polymer composites. These pores caused an increase in the porosity in consistence with graphene concentration increment, where the overall porosity was generally around $8 \%$ [31].

On the contrary, the neat resin prototypes reported better mechanical properties (as compared to the graphene/resin composite) irrespective of the layer heights. The Young's modulus and UTS have revealed a difference of $33.41 \%$ and $62.92 \%$, respectively, between the highest (in $35 \mu \mathrm{m}$ neat resin) and lowest (in $100 \mu \mathrm{m}$ graphene $1 \mathrm{wt} \%$ ) given values (See Figure 6 (a) and (b)). Meanwhile, the distinction between the highest (in $100 \mu \mathrm{m}$, neat resin) and lowest (in $100 \mu \mathrm{m}$, graphene $1 \mathrm{wt} \%$ ) values were approaching $41.97 \%$ and $57.01 \%$ for the elongation at UTS and elongation at break, sequentially (See Figure 6 (c) and (d)). The reduction values (variance) overall reviewed mechanical characteristics (Young's modulus, UTS, elongation at UTS, and elongation at break) in terms of the effect of layer thickness and the graphene incorporation are listed in Tables 4 and 5, 
consecutively. The $35 \mu \mathrm{m}$ layer thickness specimens (in Table 4) and neat resin specimens (in Table 5) of each used parameter were considered the reference for comparing.

Table 4

Variance in values regarding the layer thickness effect as compared to the reference specimen ( $35 \mu \mathrm{m}$ layer thickness, highlighted with blue color) of each condition

\begin{tabular}{|c|c|c|c|c|c|}
\hline \multicolumn{2}{|c|}{ Printing parameter } & \multicolumn{4}{|c|}{ Variance in values } \\
\hline $\begin{array}{c}\text { Graphene } \\
\text { concentration } \\
(\mathbf{w t} \%)\end{array}$ & $\begin{array}{c}\text { Layer } \\
\text { thickness } \\
{[\boldsymbol{\mu m}]}\end{array}$ & $\begin{array}{c}\text { Young's } \\
\text { modulus }\end{array}$ & UTS & $\begin{array}{c}\text { Elongation } \\
\text { at UTS }\end{array}$ & $\begin{array}{c}\text { Elongation } \\
\text { at break }\end{array}$ \\
\hline \multirow{3}{*}{0} & 35 & $917.66[\mathrm{MPa}]$ & $49.17[\mathrm{MPa}]$ & $5.39[\%]$ & $6.79[\%]$ \\
\cline { 2 - 6 } & 50 & $-7.65 \%$ & $-8.14 \%$ & $-1.11 \%$ & $+8.98 \%$ \\
\cline { 2 - 6 } & 100 & $-8.27 \%$ & $-8.16 \%$ & $+1.67 \%$ & $+9.28 \%$ \\
\hline \multirow{3}{*}{0.5} & 35 & $890.87[\mathrm{MPa}]$ & $28.74[\mathrm{MPa}]$ & $3.23[\%]$ & $3.24[\%]$ \\
\cline { 2 - 6 } & 50 & $-2.92 \%$ & $+21.15 \%$ & $+26.63 \%$ & $+26.23 \%$ \\
\cline { 2 - 6 } & 100 & $-9.40 \%$ & $-7.24 \%$ & $+2.17 \%$ & $+2.16 \%$ \\
\hline \multirow{3}{*}{1} & 35 & $715.85[\mathrm{MPa}]$ & $29.76[\mathrm{MPa}]$ & $4.23[\%]$ & $4.27[\%]$ \\
\cline { 2 - 6 } & 50 & $-11.18 \%$ & $-31.01 \%$ & $-23.88 \%$ & $-24.59 \%$ \\
\cline { 2 - 6 } & 100 & $-14.64 \%$ & $-38.74 \%$ & $-24.82 \%$ & $-25.29 \%$ \\
\hline
\end{tabular}

Table 5

Variance in values concerning the graphene addition effect as compared to the reference specimen (neat resin material " 0 graphene concentration", highlighted with blue color) of each condition

\begin{tabular}{|c|c|c|c|c|c|}
\hline \multicolumn{2}{|c|}{ Printing parameter } & \multicolumn{4}{|c|}{ Variance in values } \\
\hline $\begin{array}{c}\text { Layer } \\
\text { thickness } \\
{[\boldsymbol{\mu m}]}\end{array}$ & $\begin{array}{c}\text { Graphene } \\
\text { concentration } \\
(\mathbf{w t} \%)\end{array}$ & $\begin{array}{c}\text { Young's } \\
\text { modulus }\end{array}$ & UTS & $\begin{array}{c}\text { Elongation } \\
\text { at UTS }\end{array}$ & $\begin{array}{c}\text { Elongation } \\
\text { at break }\end{array}$ \\
\hline \multirow{3}{*}{35} & 0 & $917.66[\mathrm{MPa}]$ & $49.17[\mathrm{MPa}]$ & $5.39[\%]$ & $6.79[\%]$ \\
\cline { 2 - 6 } & 0.5 & $-2.92 \%$ & $-41.55 \%$ & $-40.07 \%$ & $-52.28 \%$ \\
\cline { 2 - 6 } & 1 & $-21.99 \%$ & $-39.48 \%$ & $-21.52 \%$ & $-37.11 \%$ \\
\hline \multirow{3}{*}{50} & 0 & $847.46[\mathrm{MPa}]$ & $45.17[\mathrm{MPa}]$ & $5.33[\%]$ & $7.40[\%]$ \\
\cline { 2 - 6 } & 0.5 & $+2.04 \%$ & $-22.91 \%$ & $-23.26 \%$ & $-44.73 \%$ \\
\hline \multirow{3}{*}{100} & 1 & $-24.98 \%$ & $-54.55 \%$ & $-39.59 \%$ & $-56.48 \%$ \\
\cline { 2 - 6 } & 0 & $841.78[\mathrm{MPa}]$ & $45.16[\mathrm{MPa}]$ & $5.48[\%]$ & $7.42[\%]$ \\
\cline { 2 - 6 } & 0.5 & $-4.12 \%$ & $-40.97 \%$ & $-39.78 \%$ & $-55.39 \%$ \\
\hline
\end{tabular}

A similar attitude was recognized by some researchers in recently published studies when mechanical properties of 3D printed graphene/polymer composites were investigated. A reduction in the tensile strength, the flexural strength, the tensile modulus of elasticity, and the flexural modulus of elasticity was detected with the increase in the graphene nanoplatelets $(\mathrm{GnP})$ concentration [37] uploaded to ABS polymer. The mechanical response and tensile strength of a pure 
thermoplastic PLA proved a better performance as compared to graphene/PLA composite [38]. The addition of $0.5 \%$ of graphene oxide (GO) to the matrix of DLP 3D printed resin caused a decrease of the mechanical features, as a higher amount of GO negatively influenced the curing process [33]. Several parameters can influence the mechanical characteristics of graphene-based composites including the preparation method, the structure of the filler, the dispersion of the graphene in the matrix, the orientation of the nanoplatelets (filler), and the filler matrix interactions [3]. In terms of the preparation methods effect, many studies have reviewed the mechanical properties of graphene-based polymer composites prepared with various procedures other than $3 \mathrm{D}$ printing. Vallés et al. have incorporated graphene oxide (GO) into an epoxy resin (matrix) at loadings from 0.5 to $5 \mathrm{wt} \%$ using sonication bath and then mechanical stirring. Tensile testing revealed moderate reinforcement of the polymer up to an optimal loading of 1 wt $\%$. However, higher loadings beyond $1 \mathrm{wt} \%$ caused the mechanical features of the composites to deteriorate due to agglomeration of the GO flakes [39]. Another published research reported a comparable approach when polyurethane (PU) nanocomposites incorporated with graphene sheets (D-Graphene) by solution blending method. For this composite (D-Graphene/PU), the tensile strength enhanced up to a certain limit of graphene loading $(0.24 \mathrm{vol} \%)$ but then reduced as loading increased [40]. This indicates that neither 3D printing nor other preparation methods can be considered free of disadvantages while graphene incorporated in a composite form. As 3D printing suffered from porosity existing whereas other methods showed filler flakes agglomeration which both contributed to weakening the mechanical features. Nevertheless, 3D printing has the advantage of manufacturing complex structures with a relatively shorter time and less material consumption.

\section{Conclusions}

In this work, the mechanical properties of 3D printed, neat resin and graphene/resin composite, using the DLP printing method were studied. Three printing layer thicknesses $(35,50,100 \mu \mathrm{m})$ were used, during the fabrication of specimens and two different graphene concentrations $(0.5$ and $1 \mathrm{wt} \%)$ were tested. The effect of 3D printing layer thickness parameters and graphene nanoplatelets subsistence, were evaluated. Based on the experimental results, the following conclusions can be formed:

- The SEM images revealed that the graphene nanoplatelets were successfully incorporated into the printed structure. Furthermore, the graphene was properly dispersed throughout the specimen's bulk.

The highest tensile strength attitude was observed in the lowest layer thickness $(35 \mu \mathrm{m})$ specimens, due to the increase in the number of layers. The greatest decrease $(35.52 \%)$ was noticed in the $100 \mu \mathrm{m}$ layer thickness, against the $35 \mu \mathrm{m}$ (at $1 \mathrm{wt} \%$ graphene content samples). 
- The graphene contributed to scattering the UV light and decreased the curing, which resulted in the presence of adjacent unpolymerized regions. As a result it played a role in boosting the porosity of the material.

The mechanical properties was not improved, when the graphene nanoplatelets were integrated throughout the obtained results. Also, a much worse mechanical attitude was gained when increasing the graphene concentration further, owing to the porosity increase.

The neat resin test pieces reported better mechanical properties (in terms of Young's modulus, UTS, elongation at UTS, and elongation at break) as compared to the graphene/resin composite, irrespective of the layer heights. The greatest difference of $33.41 \%$ and $62.92 \%$ concerning Young's modulus and UTS, respectively, between the highest (neat resin) and lowest (graphene $1 \mathrm{wt} \%$ ) obtained values. Meanwhile, the variance was approaching $41.97 \%$ and $57.01 \%$ for the elongation at UTS and elongation at break, sequentially.

Obviously, with the addition of Graphene, as the rigid reinforcement to the polymer, caused a decrease in ductility. However, this can lead to the proposal, that the resultant graphene/polymer composite, may be a potential material, for sliding bearing applications, where the tribological properties, are much more important than the mechanical properties.

\section{Acknowledgement}

This work was supported by Szent István Campus, MATE University Research Fund (project number VEKOP-2.2.1-16-2017-00004), and the Stipendium Hungaricum Programme, Hungary.

\section{References}

[1] Kinloch I. A., Suhr J., Lou J., Young R. J., Ajayan P. M., "Composites with carbon nanotubes and graphene: An outlook”, Science, Vol. 362, No. 6414, pp. 547-553, 2018

[2] Guo H., Lv R., Bai S., "Recent advances on 3D printing graphene-based composites”, Nano Materials Science, Vol. 1, No. 2, pp. 101-115, 2019

[3] Papageorgiou D. G., Kinloch I. A., Young R. J., "Mechanical properties of graphene and graphene-based nanocomposites", Progress in Materials Science, Vol. 90, pp. 75-127, 2017

[4] Kátai L., Szabó I., Lágymányosi A., Lágymányosi P., Szakál Z., "Investigating the strength properties of a material used in additive manufacturing technology depending on the parameters of 3D printing", Gép, Vol. LXIX, No. 4, pp. 45-48, 2018

[5] Erdős F., Németh R., "AMT-based real-time, inter-cognitive communication model”, Acta Polytechnica Hungarica, Vol. 16, No. 6, pp. 115-127, 2019 
[6] Rafajłowicz E., "Data Structures for Pattern and Image Recognition and Application to Quality Control", Acta Polytechnica Hungarica, Vol. 15, No. 4, pp. 233-262, 2018

[7] Chaczko Z., Klempous R., Rozenblit J., Adegbija T., Chiu C., Kluwak K., Smutnick C., "Biomimetic Middleware Design Principles for IoT Infrastructures", Acta Polytechnica Hungarica, Vol. 17, No. 5, pp. 135-150, 2020

[8] Madhav C. V., Kesav R. S. N. H., Narayan Y. S., Importance and Utilization of 3D Printing in Various Applications (2016)

[9] Balletti C., Ballarin M., Guerra F., "3D printing: State of the art and future perspectives", Journal of Cultural Heritage, Vol. 26, pp. 172-182, 2017

[10] Bártolo P. J., Stereolithography: Materials, Processes and Applications, Springer US, Boston, MA, (2011)

[11] Mu Q., Wang L., Dunn C. K., Kuang X., Duan F., Zhang Z., Qi H. J., Wang T., "Digital light processing 3D printing of conductive complex structures", Additive Manufacturing, Vol. 18, pp. 74-83, 2017

[12] Hanon M. M., Zsidai L., "Sliding surface structure comparison of 3D printed polymers using FDM and DLP technologies", IOP Conference Series: Materials Science and Engineering, Vol. 749, pp. 012015, 2020

[13] Wu G.-H., Hsu S., "Review: Polymeric-Based 3D Printing for Tissue Engineering", Journal of Medical and Biological Engineering, Vol. 35, No. 3, pp. 285-292, 2015

[14] Hanon M. M., Zsidai L., "Tribological and mechanical properties investigation of 3D printed polymers using DLP technique", AIP Conference Proceedings, Vol. 2213, pp. 020205, 2020

[15] Xu Z., Gao C., "In situ Polymerization Approach to Graphene-Reinforced Nylon-6 Composites", Macromolecules, Vol. 43, No. 16, pp. 6716-6723, 2010

[16] Lin D., Jin S., Zhang F., Wang C., Wang Y., Zhou C., Cheng G. J., “3D stereolithography printing of graphene oxide reinforced complex architectures", Nanotechnology, Vol. 26, No. 43, pp. 434003, 2015

[17] Verdejo R., Bernal M. M., Romasanta L. J., Lopez-Manchado M. A., "Graphene filled polymer nanocomposites", J. Mater. Chem., Vol. 21, No. 10 , pp. 3301-3310, 2011

[18] Mohan V. B., Bhattacharyya D., "Mechanical, electrical and thermal performance of hybrid polyethylene-graphene nanoplatelets-polypyrrole composites: a comparative analysis of 3D printed and compression molded samples", Polymer-Plastics Technology and Materials, Vol. 59, No. 7, pp. 780-796, 2020 
[19] Prashantha K., Roger F., "Multifunctional properties of 3D printed poly(lactic acid)/graphene nanocomposites by fused deposition modeling", Journal of Macromolecular Science, Part A, Vol. 54, No. 1, pp. 24-29, 2017

[20] Mansour M., Tsongas K., Tzetzis D., "Measurement of the mechanical and dynamic properties of 3D printed polylactic acid reinforced with graphene", Polymer-Plastics Technology and Materials, Vol. 58, No. 11, pp. 12341244,2019

[21] Del Gaudio C., "A feasibility study for a straightforward decoration of a 3D printing filament with graphene oxide", Fullerenes, Nanotubes and Carbon Nanostructures, Vol. 27, No. 8, pp. 607-612, 2019

[22] Tiwari J. K., Mandal A., Sathish N., Agrawal A. K., Srivastava A. K., "Investigation of porosity, microstructure and mechanical properties of additively manufactured graphene reinforced AlSi10Mg composite", Additive Manufacturing, Vol. 33, pp. 101095, 2020

[23] Esun Industrial Co. L., eResin-LC1001, Material Safety Data Sheet, Shenzhen, China (2019)

[24] Inc. N. N., Graphene Nanoplatelet-NG01GNP0109, Material Safety Data Sheet, Ankara, Turkey (2019)

[25] Formlabs, Form Cure Time and Temperature Settings (2018)

[26] International Organization for Standardization, ISO 527-2:2012: Plastics Determination of tensile properties - Part 2: Test conditions for moulding and extrusion plastics (2012)

[27] Hanon M. M., Marczis R., Zsidai L., “Anisotropy Evaluation of Different Raster Directions, Spatial Orientations, and Fill Percentage of 3D Printed PETG Tensile Test Specimens", Key Engineering Materials, Vol. 821, pp. 167-173, 2019

[28] Hanon M. M., Alshammas Y., Zsidai L., "Effect of print orientation and bronze existence on tribological and mechanical properties of 3D-printed bronze/PLA composite", The International Journal of Advanced Manufacturing Technology, Vol. 108, No. 1-2, pp. 553-570, 2020

[29] Hanon M. M., Marczis R., Zsidai L., "Influence of the 3D Printing Process Settings on Tensile Strength of PLA and HT-PLA", Periodica Polytechnica Mechanical Engineering, Vol. 65, No. 1, pp. 38-46, 2020

[30] International Organization for Standardization, ISO 527-1:2012 - Plastics -Determination of tensile properties -- Part 1: General principles (2012)

[31] Markandan K., Lai C. Q., "Enhanced mechanical properties of 3D printed graphene-polymer composite lattices at very low graphene concentrations", Composites Part A: Applied Science and Manufacturing, Vol. 129, pp. 105726, 2020 
[32] Lai C. Q., Markandan K., Luo B., Lam Y. C., Chung W. C., Chidambaram A., "Viscoelastic and high strain rate response of anisotropic graphenepolymer nanocomposites fabricated with stereolithographic 3D printing", Additive Manufacturing, Vol. 37, pp. 101721, 2021

[33] Chiappone A., Roppolo I., Naretto E., Fantino E., Calignano F., Sangermano M., Pirri F., "Study of graphene oxide-based 3D printable composites: Effect of the in situ reduction", Composites Part B: Engineering, Vol. 124, pp. 9-15, 2017

[34] Sood A. K., Ohdar R. K., Mahapatra S. S., "Experimental investigation and empirical modelling of FDM process for compressive strength improvement", Journal of Advanced Research, Vol. 3, No. 1, pp. 81-90, 2012

[35] Ayrilmis N., Kariz M., Kwon J. H., Kitek Kuzman M., "Effect of printing layer thickness on water absorption and mechanical properties of 3Dprinted wood/PLA composite materials", The International Journal of Advanced Manufacturing Technology, Vol. 102, No. 5-8, pp. 2195-2200, 2019

[36] Rankouhi B., Javadpour S., Delfanian F., Letcher T., "Failure Analysis and Mechanical Characterization of 3D Printed ABS With Respect to Layer Thickness and Orientation", Journal of Failure Analysis and Prevention, Vol. 16, No. 3, pp. 467-481, 2016

[37] Vidakis N., Maniadi A., Petousis M., Vamvakaki M., Kenanakis G., Koudoumas E., "Mechanical and Electrical Properties Investigation of 3DPrinted Acrylonitrile-Butadiene-Styrene Graphene and Carbon Nanocomposites", Journal of Materials Engineering and Performance, Vol. 29, No. 3, pp. 1909-1918, 2020

[38] Vidakis N., Petousis M., Savvakis K., Maniadi A., Koudoumas E., “A comprehensive investigation of the mechanical behavior and the dielectrics of pure polylactic acid (PLA) and PLA with graphene (GnP) in fused deposition modeling (FDM)", International Journal of Plastics Technology, Vol. 23, No. 2, pp. 195-206, 2019

[39] Vallés C., Beckert F., Burk L., Mülhaupt R., Young R. J., Kinloch I. A., "Effect of the $\mathrm{C} / \mathrm{O}$ ratio in graphene oxide materials on the reinforcement of epoxy-based nanocomposites", Journal of Polymer Science Part B: Polymer Physics, Vol. 54, No. 2, pp. 281-291, 2016

[40] Yang L., Phua S. L., Toh C. L., Zhang L., Ling H., Chang M., Zhou D., Dong Y., Lu X., "Polydopamine-coated graphene as multifunctional nanofillers in polyurethane", RSC Advances, Vol. 3, No. 18, pp. 6377, 2013 